\title{
Reinventando las organizaciones
}

\section{Reinventing Organizations}

\author{
Juan Carlos Robledo Fernández \\ Red Mexicana de Investigadores en Estudios Organizacionales (REMIINEO), México.
}

Los desafíos del siglo XXI en términos económicos y empresariales nunca habían estado tan vinculados al mundo de las organizaciones, en especial la visión tradicional del mundo que aún se maneja en muchas partes se traduce en retos a la creatividad y la imaginación del mundo gerencial particularmente en el problema de la organización con respecto al trabajo de las personas. Esto lleva al tema planteado por Frederick Laloux el cual cuestiona si ¿Podemos crear organizaciones libres de las patologías que pueden surgir en los lugares de trabajo, libres de burocracia, disputas de poder, libres de estrés y fatiga, resentimientos o apatía? Además, complementando esta cuestión: "¿Es posible tener organizaciones altamente competitivas sin perder la perspectiva de la persona humana que en ella habita?

La cuestión es que, sí es posible tener un mundo mejor desde el diseño organizacional desprovisto de las "tiranías del poder managerial" y constituido por una amplia capacidad de reconocimiento de las capacidades del otro, de los otros, y en conjunto de nosotros. Es una invitación a un nuevo management, uno mayormente centrado en las personas antes que, en las cosas, centrado en el valor integral antes que solo en el valor económico.

De este modo, la revista Desarrollo Gerencial como medio de difusión científica invita a todos los investigadores en el campo de las organizaciones, la gestión, la estrategia y las ciencias económicas y administrativas en general a que aporten sus valiosas ideas para fortalecer el estatuto científico en estudios organizacionales, empresariales y gerenciales, más amplio, capaz de llenar los vacíos de las inclinaciones meramente positivistas, recogiendo en parte lo mencionado por Albert Einstein cuando dijo: "La mente intuitiva es un don sagrado y la mente racional es un fiel servidor. Hemos creado una sociedad que honra al sirviente y ha olvidado el don".

El desafío superior en el mundo de las organizaciones se focaliza hoy en una economía que está altamente influida por la ciencia, la tecnología, la inteligencia artificial, un mundo de redes, entre otras formas de avance. Sin embargo, ¿La persona humana que rol jugara en este nuevo escenario? ¿Cuál es el nuevo management del siglo XXI? 
Es un hecho, las organizaciones seguirán en nuestro mundo porque sin ellas las sociedades humanas no tendrían como construir capacidades, desarrollar la ciencia y la tecnología, sin ellas, las personas estarían sin rumbo. Sin embargo, es también un hecho que las tensiones económicas, de mercado y competitividad han construido y siguen construyendo realidades organizacionales diversas, heterogéneas, que enfrentan a las organizaciones a situaciones algunas específicas y otras generales. Es por ello que pensar en tener una teoría general y universal de las organizaciones sería una tarea utópica. Y es precisamente este aspecto utópico el que más inspira para seguir en la búsqueda de nuevos paradigmas organizacionales que respondan a las dinámicas de un mundo cambiante, de un mundo que globalizado esta paradójicamente fragmentado.

De otra parte, está el lado humano que habita al interior de las organizaciones. Un lugar en el que las personas se conducen por diversos intereses, un lugar desde donde se hacen manifiestos elementos que pueden ser estudiados con rigor por la sociología, la antropología, la psicología, en una perspectiva que puede ir más allá de las tensiones "cientificistas" que se están imponiendo hoy en día al cuerpo de investigadores en las universidades. Y me refiero muy específicamente a la "trampa socio-institucional" en la que al menos en América Latina están cayendo sin reflexión muchas universidades al forzar a sus profesores a buscar el desarrollo de la investigación solo con el propósito de alcanzar ranking por revistas de alta indexación, perdiendo de vista, que al menos el carácter de la investigación en las ciencias sociales construye su objeto científico en la misma esencia que le subyace, y que los afanes "cientificistas" vienen levantando barreras al desarrollo de un pensamiento nuevamente libre, autónomo y brillante, como lo era otrora los grandes pensadores en el campo de las ciencias sociales.

Por ello, la visión mecanicista de las organizaciones ha llegado realmente a sus límites y no es capaz de explicar fenómenos orgánicos que hoy emergen como el paradigma de las organizaciones tipo TEAL. De hecho, la visión mecanicista es un obstáculo al desarrollo mismo del campo de la estrategia empresarial al sujetarlo a condiciones positivistas.

El futuro de las organizaciones esta por tanto adherido al futuro de lo humano, al desarrollo de la ciencia y la tecnología, a la reflexión crítica, a la concepción de nuevas ideas, premisas, hipótesis, tesis y antítesis del conocimiento organizacional y por ende el de la Administración. Bienvenidas sean entonces la diversidad y posturas del pensamiento científico, en todos hay riqueza, oportunidad y reflexión. No es uno mejor que el otro, son todos necesarios para el dialogo, el debate y la apertura a nuevas oportunidades del pensamiento científico en las ciencias sociales. 